\title{
Subgingival microbiota of renal transplant recipients
}

W.K. Leung ${ }^{1}$, J.Y.Y. Yau ${ }^{1}$, L.J. Jin ${ }^{1}$, A.W.K. Chan ${ }^{1}$, F.C.S. Chu ${ }^{1}$, C.S.P. Tsang ${ }^{1}$, T.M. Chan ${ }^{2}$

${ }^{1}$ Faculty of Dentistry, and ${ }^{2}$ Division of Nephrology, Department of Medicine, Faculty of Medicine, The University of Hong Kong, Hong Kong SAR, China

KEY WORDS: Anaerobic bacteria, gingival overgrowth, kidney transplantation, periodontal diseases

RUNNING HEAD: subgingival flora post-renal transplant 


\begin{abstract}
Leung WK, Yau JYY, Jin LJ, Chan AWK, Chu FCS, Tsang CSP, Chan TM. Subgingival microbiota of renal transplant recipients. Oral Microbiol Immunol

Renal transplant patients undergoing immunosuppressive therapy may experience periodontal side effects such as gingival overgrowth. This study evaluated the subgingival microbiota of renal transplant recipients with or without periodontal tissue destruction who may have concurrent gingival enlargement. Subgingival paper point samples taken from the deepest probing sites of 38 subjects (one per patient) were examined using direct microscopy and culture techniques. A complex microflora comprising gram-positive and gram-negative cocci, rods and filaments, fusiforms, curved rods and spirochetes was observed using micrscopy. Yeasts were occasionally detected. Significantly higher proportions of gram-positive morphotypes including gram-positive cocci were observed in samples from periodontally healthy patients. The predominant cultivable microflora from anaerobic culture comprised several species of facultative and obligate anaerobes. Colonization of the subgingival sites by 'foreign' microbes that are normal dermal, intestinal or vaginal flora was detected in up to $50 \%$ of the samples. High mean proportions of lost or unidentified species was also noted occasionally. The results showed that the subgingival biofilm of renal transplant recipients with chronic periodontitis comprised mainly gram-negative rods and spirochetes. Besides the usual predominant cultivable subgingival microbiota associated with periodontitis, the high prevalence of unidentified and 'foreign' microbes indicates the possibility of subgingival microbial alteration in renal transplant patients.
\end{abstract}


Corresponding author

W. Keung Leung, Faculty of Dentistry, The University of Hong Kong, Room 3B39, 34 Hospital Road, Hong Kong SAR, China

Tel: (852) 2859-0417

Fax: (852) 2858-7874

E-mail: ewkleung@hkucc.hku.hk 
Renal transplantation offers rehabilitation of individuals diagnosed for end-stage renal failure (4). Renal replacement therapy was introduced in Hong Kong public hospitals 24 years ago (5). Immunosuppression therapy by glucocorticoids, azathioprine, cyclosporin, tacrolimus, mycophenolate mofetil, anti-CD3 antibody or antilymphocyte globulin has effectively reduced acute transplant rejection $(7,10,23)$. Cyclosporin A seems to interfere at the early phase of T-cell activation. After complexing with cyclophilin, cyclosporin A inhibits the phosphatase calcineurin which, in turn, blocks the cytokine gene activation and hence exerts an immunosuppression function (35). The major draw-backs of cyclosporin $\mathrm{A}$ are opportunistic infections, predisposition to lymphoreticular and epidermal malignancies, neuroectodermal problems including gingival overgrowth and mesenchymal disorders such as hypertension (18). Tacrolimus, another immunosuppression agent introduced in 1994 also inhibits calcineurin and prevents allograft rejection, but is associated with less gingival enlargement (3).

Gingival overgrowth is one of the most important complications for renal transplant recipients $(6,33)$. Poor plaque control and pre-transplant and/or concurrent gingival inflammation are associated with gingival overgrowth in renal transplant recipient. (28). However, improved oral hygiene alone may not be sufficient to prevent gingival overgrowth $(28,29,38)$.

The present report is part of a project which focused on the oral health status and the treatment needs of post-operative, stable renal transplant recipients in Hong Kong. The prevalence of gingival overgrowth in the present study subjects was high (53\%) (6) comparable to reports from other parts of the world $(12,33)$. This study investigated the subgingival microflora of renal transplant recipients with or without periodontal tissue destruction who may or may not be affected by gingival enlargement. 


\section{Material and Methods}

\section{Subjects, study groups and sample sites selection}

From a pool of 60 subjects who participated in an oral health status survey (6), 45 subjects (19 women, age $21-68$ years) consented to the microbiological study. They were Chinese patients attending for regular review at the Nephrology Clinic of the Department of Medicine, Queen Mary Hospital, Faculty of Medicine, the University of Hong Kong. All subjects received renal transplant at least 6 months before recruitment, were deemed to have stable renal functions and did not require antibiotic prophylaxis for dental procedures. Dental histories were taken to exclude individuals undergoing regular dental care. Recruited subjects should not be under antimicrobial therapy currently or during the preceding 4-week period. The research protocol was approved by the University of Hong Kong, Faculty of Dentistry Ethics Committee and informed consent was obtained from participants.

Full mouth manual periodontal examination was carried out to identify the subgingival sample site. Standard panoramic and periapical radiographs were taken to assess the alveolar bone conditions. The subjects were segregated into 2 groups: i) subjects without radiographic signs of alveolar bone loss, i.e. without periodontal destruction (Group A) subjects could be without (subgroup $A_{1}$ ) or with (subgroup $A_{2}$ ) gingival overgrowth; ii) subjects with radiographic signs of alveolar bone loss $(\geq 10 \%)$ around at least one tooth per quadrant, i.e. periodontal destruction is evident (Group B) - subjects could be without (subgroup $\mathrm{B}_{1}$ ) or with (subgroup $\mathrm{B}_{2}$ ) gingival overgrowth.

Subgingival plaque samples were collected from the deepest probing depth sites (one per subject) from all recruits including sites with or without gingival overgrowth. For subjects who had shallow probing depth measurements (PD $\leq 3 \mathrm{~mm}$ ), a labial surface of any one of 
the incisors or canines was chosen at random for convenience to be the sample site. The samples were used for microscopy and culture study. After sampling, the probing pocket depths of the sampled sites were measured by an electronic probe system (Florida Probe ${ }^{\circledR}$, Gainesville, FL) to reconfirm the clinical conditions of the sites sampled.

\section{Microbiological sampling}

The subgingival microbiological sampling was performed as described previously using 4 sterile endodontic paper points (medium absorbent points, Kerr), inserting 2 at a time to the depth of the sulcus/pocket with 20 seconds sampling time (16). All paper point samples were put into one coded bottle with $3 \mathrm{ml}$ reduced transport fluid. The bottle was then transported immediately to the laboratory, where the specimen was processed within 30 to 60 min by JYYY, who was blind to the clinical data and subject grouping.

\section{Direct microscopy}

The paper point samples in reduced transport fluid were dispersed by vortexing (Autovortex Mixer SA2, Stuart Scientific, London, UK), at maximum setting for $15 \mathrm{~s}$. A total of $15 \mu 1$ of the dispersed suspension was transferred and smeared onto a clean glass slide for Gramstaining and examination. The differential counts of various microbial morphotypes were conducted as described previously using a light microscope (Nikon 104) at $\times 1000$ magnification (16).

\section{Anaerobic culture}

The rest of the dispersed microbial suspension was serially diluted and inoculated onto Columbia blood agar base (Difco Laboratories) supplemented with $5 \%$ defibrillated horse blood, $5 \mathrm{mg} / \mathrm{l}$ hemin and $500 \mu \mathrm{g} / \mathrm{l}$ menadione (CBABS) using a spiral plater (Spiral System, 
Cincinnati, $\mathrm{OH})$. The plates were incubated for $5-7$ days at $37^{\circ} \mathrm{C}$ in an anaerobic chamber (Forma Scientific, Marietta, $\mathrm{OH}$ ) under an atmosphere of $80 \% \mathrm{~N}_{2}, 10 \% \mathrm{H}_{2}$ and $10 \% \mathrm{CO}_{2}$. Anaerobiosis of the chamber was monitored daily using disposable anaerobic indicator strips (BBL, Becton Dickinsan, Maryland). After incubation, plates with colonies that were well separated and evenly dispersed were selected and a stainless steel template was used to subdivide the agar surface into sectors with a defined area. The relative proportions of all different colony morphotypes were determined. Representative colonies were subcultured as described by McNabb et al. (19) on CBABS plates to obtain pure cultures. The colonyforming units of these representative colonies and the dilution factor of the inoculum were recorded for later quantification. All dispersion, plating and subculturing were done on a laboratory bench.

\section{Selective culture of aerobic and facultative anaerobic gram-negative rods and yeasts}

The dispersed microbial suspension was inoculated by spiral plating onto duplicate MacConkey agar and Sabouraud's dextrose agar (Oxoid, Hampshire, United Kingdom) plates and incubated for $18 \mathrm{~h}$ at $37^{\circ} \mathrm{C}(14,17)$. Cultures were examined and the colony-forming units of representative colonies and dilution factor of the inoculum were noted. The aerobic and facultative anaerobic gram-negative rods and yeasts colonies were subcultured on their respective culture media to obtain pure isolates.

\section{Identification of isolates}

Isolates were identified presumptively using colony morphology, hemolysis and pigmentation, cell morphology, catalase and oxidase tests and the ability to grow in air supplemented with $10 \% \mathrm{CO}_{2}(31)$. Additional tests for the facultative anaerobic gram-positive cocci included the colony morphology on mitis-salivarius agar (Difco Laboratories) and characterization by 
using API 20 Strep and API Staph kits (Analytical Profile Index, BioMérieux, SA, France). Additional tests for the facultative anaerobic gram-negative rods were glucose fermentation and motility in a semi-solid medium (31). Facultative anaerobic gram-negative fusiforms were further characterized as per Koneman et al. (13). Obligate anaerobes were characterized using the RapID ANAII system (Innovative Diagnostic Systems, Norcross, GA) and for motility in a semi-solid medium (31). The corresponding quantitative/percentage proportion data (colony-forming units per paper point/percentage proportion of the identified species per total count of the sample) of individual species isolated were then calculated.

Isolates were further characterized biochemically using the API 20E kit. Pure culture of yeasts was identified based on colony morphology, cell morphology, Gram staining reaction, germ tube test (14) and API 20C AUX and API ZYM tests.

\section{Statistics}

The demographic and microbiological data of the groups A and B were analyzed by Statview 4.5 for Macintosh. Difference between groups was tested by analysis of variance (Group A against group B) or Fisher's exact test, as appropriate. The bacteriological data of the four subgroups according to the presence/absence of periodontal destruction and presence/absence of concurrent gingival overgrowth, i.e. subgroup $A_{1}, A_{2}$ and $B_{1}, B_{2}$ were analyzed using Bonferroni's multiple comparison. Groups or subgroups were regarded as significantly different from each other if $P$ was $<0.05$.

\section{Results}

\section{Clinical Findings}

Out of 45 individuals who consented and were invited for the study, 38 subjects remained eligible (Table 1) Five subjects were rejected because they were either under regular dental 
care or were taking antibiotics. Two subjects, whose deepest probing depth sites were associated with impacted mandibular third molars, were excluded. No recruits had received more than emergency dental treatment during the preceding 24 months (6). Relevant periodontal data are shown in Table 2. Moderate periodontal problems inclusive of gingival overgrowth was diagnosed in $89 \%$ of the subjects. Sixty four percent $(n=7)$ of group A subjects were affected by gingival overgrowth while $41 \%(n=11)$ of group B subjects also displayed gingival overgrowth with various level of periodontal destruction.

\section{Direct Microscopy}

As shown in Table 3, a total of 9 microbial morphotypes could be recognized. Gramnegative rods were observed in all samples while the prevalences of gram-negative cocci, curved rods and spirochetes were more than $80 \%$. Prevalences of gram-positive cocci and fusiforms were more than $60 \%$. Gram-negative filaments were observed in about $50 \%$ of the samples while the prevalence of gram-positive rods in groups A and B was $32 \%$ and $63 \%$ respectively. Gram-positive coccal morphotypes as well as the proportions of total grampositive species were significantly higher in group A compared to group B. The proportion of other microorganisms were similar in both groups.

When groups A or B were further subdivided according to presence or absence of gingival overgrowth, group A subjects without any gingival overgrowth (subgroup $A_{1}$ ) were found to have significantly greater percentage proportion of gram-positive cocci $(33.3 \pm$ $22.2 \%$ ) than that in group $A$ subjects with gingival overgrowth (subgroup $A_{2} ; 5.3 \pm 13.1 \%$ ), and group $B$ subjects without (subgroup $B_{1} ; 11.2 \pm 14.5 \%$ ) or with (subgroup $B_{2} ; 0.0 \pm 0.0 \%$ ) gingival overgrowth $(P=0.003$, Bonferroni multiple comparison). Samples from subgroup $A_{1}$ subjects were also found to comprise a lesser proportion of curved rods $(0.9 \pm 0.8 \%)$ than subgroup $B_{1}$ subjects $\left(13.7 \pm 12.7 \%\right.$; subgroup $A_{2}=22.1 \pm 16.4 \%$; subgroup $B_{2}=3.3 \pm 1.1 \%$, 
$P=0.029$, Bonferroni multiple comparison). Overall, samples from subgroup $\mathrm{A}_{1}$ had greater proportions of total gram-positive species $\left(37.6 \pm 26.1 \%\right.$ vs subgroup $A_{2}=6.3 \pm 15.6 \%$; subgroup $\mathrm{B}_{1}=13.8 \pm 18.6 \%$ or subgroup $\mathrm{B}_{2}=0.5 \pm 0.7 \%, P=0.008$, Bonferroni multiple comparison).

\section{Anaerobic Culture}

Following purification, a total of 279 isolates were obtained from the 38 samples. The total number of isolates obtained from the 2 groups was similar as well as the number of identifiable species (Group $A=6.5$; Group $B=7.7$ ). Fifty six isolates, however, were lost or could not be identified.

Marked sample-to-sample variations were observed among the 2 groups regarding the total quantity of predominant cultivable facultative and obligate anaerobic bacteria. The mean colony-forming units/paper point for the groups A and B was $2.4 \times 10^{7} \pm 3.9 \times 10^{7}$ and $5.5 \times 10^{7} \pm 9.0 \times 10^{7}$, respectively. No significant difference was detectable in total quantity of mincree; or data values for microbial subcategories between groups A and B because of the large data ranges. When data were transformed into percentage proportions; differences in proportions could be measured (Fig. 1). Up to $50 \%$ of the isolates in the groups were facultative anaerobes, of which a greater proportion of gram-positive cocci was observed in group A. Higher proportion of total gram-positive species and hence conversely less proportion of total gram-negative species was observed in group A than in group B. That is, for gram-positive species, group A vs B: $82.6 \pm 20.1 \%$ vs $52.6 \pm 27.2 \%, P=0.002$; for gram-negative species, group A vs B: $19.1 \pm 12.1 \%$ vs $50.4 \pm 37.3 \%, P=0.01$. The total gram-positive cocci and gram-positive facultative anaerobic species were higher in group A than in group B (47.3 \pm $27.2 \%$ vs $24.8 \pm 21.3 \%, P=0.010$ and $47.7 \pm 26.2 \%$ vs $28.5 \pm 20.0 \%, P=0.019$, respectively). Up to $25 \%$ of the isolates were lost before being tested (Fig. 1). When the 
groups $\mathrm{A}$ and $\mathrm{B}$ data were subdivided accordingly with respect to absence or presence of gingival overgrowth, facultative anaerobic gram-positive cocci were found to be of a greater proportion in samples of subgroup $A_{1}$ subjects than in subgroup $B_{1}$ subjects $\left(A_{1}=45.4 \pm\right.$ $31.8 \%$ vs $\mathrm{A}_{2}=26.2 \pm 23.7 \%, \mathrm{~B}_{1}=16.2 \pm 12.1 \%$ or $\mathrm{B}_{2}=16.8 \pm 13.2 \%, P=0.036$ Bonferroni multiple comparison).

A total of 68 different organisms were identified, comprising facultative or obligatory anaerobic gram-positive cocci (23 species), gram-positive rods (16 species), gram-negative cocci (1 species), gram-negative rods (19 species), gram-negative fusiforms (7 species) and gram-negative motile rods ( 2 species). The frequently isolated bacterial species (defined here as frequency isolation $>15 \%, \mathrm{n}=20$ ) are shown in Table 4. Streptococcus constellatus was more prevalent in group $\mathrm{A}$ and its percentage proportion together with that of $S$. salivarius salivarius was also higher. When data were grouped under the same Genera, the percentage proportions of total Staphylococcus, Streptococcus and Porphyromonas species were significantly higher in group A than in group B $(9.1 \pm 15.7 \%$ vs $1.4 \pm 4.7 \%, 18.1 \pm 18.2 \%$ vs $4.5 \pm 7.0 \%$ and $4.7 \pm 12.0 \%$ vs $0.0 \pm 0.17 \%$, respectively, $P<0.05)$. Rothia dentocariosa was present only in group A samples but was undetectable by culture in group B samples while Actinomyces israelii and Campyobacter rectus were undetectable by culture in group A samples. The isolation frequency of fusiform species was found to be statistically lower in group A than group B $(27.3 \%$ vs $66.7 \%, P=0.04$, Fisher's exact test $)$. The prevalence of lost/unidentified spp. was high in both groups while the quantity of isolates lost was considerable (Table 4, Fig. 1). A significantly higher proportion of total Staphylococcus was isolated from the subgingival samples of subgroup $A_{1}$ subjects than subgroup $B_{1}$ subjects $\left(A_{1}\right.$ $=16.8 \pm 19.6 \%$ vs $\mathrm{A}_{2}=4.8 \pm 12.6 \%, \mathrm{~B}_{1}=0.9 \pm 3.6 \%$ or $\mathrm{B}_{2}=2.8 \pm 7.1 \%, P=0.038$, Bonferroni multiple comparison) while on the other hand a significantly higher proportion of 
total Fusobacterium was observed in subgroup $B_{1}$ subjects $\left(A_{1}=1.8 \pm 3.5 \%, A_{2}=0 \pm 0 \%, B_{1}\right.$ $=4.3 \pm 12.3 \%, \mathrm{~B}_{2}=0.41 \pm 1.1 \%, p<0.0001$, Bonferroni multiple comparison).

The 48 bacterial species that were isolated with a lower frequency were as follows. Facultative anaerobic gram-positive cocci: Abiotrophia adiacens, Lactococcus lactis cremoris, Leuconostoc spp., Micrococcus spp., Staphylococcus auricularis, S. cohnii cohnii, S. epidermidis, S. sciuri, S. xylosus, Staphylococus spp., Streptococcus acidominimus, $S$. intermedius, $S$. oralis, $S$. pneumoniae; facultative or obligatory anaerobic gram-positive rods: Actinomyces odontolyticus, A. meyeri, A. viscosus, Lactobacillus acidophilus, Clostridium hastiforme, Eubacterium aerofaciens, asaccharoytic Eubacterium, Propionibacterium acnes, P. propionicum; obligatory anaerobic gram-negative coccus: Veillonella spp.; facultative or obligatory anaerobic gram-negative rods: Kingella dentrificans, Neisseria lactamica, $N$. mucosa, Pasterrella pneumotropica/haemolytica, Bacteroides fragilis, B. stercoris, B. vulgatus, Porphyromonas asaccharolyticus, $P$. gingivalis, Prevotella bivia, P. buccal, P. loescheii, $P$. melaninogenica, $P$. oralis, $P$. oris; facultative or obligatory anaerobic gramnegative fusiforms: Capnocytophaga sputigena, Capnocytophaga spp., Fusobacterium motiferum, $F$. necrophorum, $F$. nucleantum; and obligatory anaerobic gram-negative motile rod: Campylobacter showae. Among all bacteria species isolated, 15\% were isolated only in group A, 47\% were isolated only in group B. No differences were found in proportion of individual cultivable species detectable when groups $\mathrm{A}$ and $\mathrm{B}$ were further subdivided into subgroups.

\section{Aerobic and facultative anaerobic gram-negative rods and yeasts}

Aerobic and facultative anaerobic gram-negative rods and yeasts species were isolated in low prevalence and quantities in the subgingival plaque samples of the renal transplant recipients. Pseudomonas fluorescens/putida was isolated from one sample of both groups. An aerobic 
and facultatively anaerobic gram-negative rod was isolated from one of the group B samples but it failed to survive the subculturing. Out of all specimens, only one sample from group B, was found to contain a yeast, Candida parapsilosis.

\section{Discussion}

Since 1977, renal medicine in Hong Kong's public hospitals advanced steadily with the aim of improving end-stage renal failure patients' medical care and their quality of life. A recent study has shown that $0.05 \%$ of the local population was affected by end-stage renal failure and about $28 \%$ of the affected individuals received renal transplantation (5). The reported mortality rate was $7.1 \%$ over six years (9). The medical care, however, is not complemented by oral health service provision. Our earlier clinical report had shown that $65 \%$ of the cohort surveyed had not seen a dentist for at least 24 months before the study (6). This probably explained why only a very small number of periodontally healthy individuals without gingival overgrowth could be recruited for this study. Such lack of oral health care for survivors of severe systemic diseases is common in Hong Kong (27) because of very limited dental service offered by the local public medical system.

The two clinical groups in this report had similar backgrounds in terms of renal transplant, immunosuppressant used and post-transplantation duration. The only outstanding character was that the renal transplant recipients who had signs of periodontal destruction (group B) were older than those without periodontal destruction (group A) (Table 1). The recruits were irregular dental attenders and their periodontal history could not be traced. It was uncertain whether the recruit's periodontal tissue destruction occurred before or after the renal transplant. Regardless of this fact, no apparent difficulty was experienced regarding attainment of the expected periodontal healing responses among patients after treatment (6), 
showing that the transplant state does not necessarily affect the subject's periodontal treatment response (11).

The present data represent, for the first time, the subgingival microbiology of renal transplant recipients who were receiving the most common combination of immunosuppressive agents, namely corticosteroids together with a calcineurin inhibitor. The data included specimens from perioodontally healthy and diseased conditions in this special patient group. The current results support the idea that considerable changes in the subgingival flora of renal transplant recipients can happen. A high prevalence and a fair percentage proportion of non-oral species were identified (Table 4). Higher than average amounts of lost/unidentified isolates were detected with anaerobic culture (Table 4, Fig. 1).

Colonization of subgingival sites by non-oral species in special patient groups has been previously reported including patients with failing hydroxyapatite-coated implants (25), compromised medical conditions $(22,30)$, HIV-infection $(24,37)$ and head and neck irradiation (16). The prevalence of such species in subgingival samples of these special groups are usually low $(<30 \%)$ and the disease conditions did not seem to confer significant influence over the regular subgingival flora. It seems as if the present study data confirmed the findings of previous publications, however, the prevalences and relative quantities of these non-oral microbes as shown in Table 4 were considerably higher.

A striking finding was that a fair proportion of the predominantly cultivable isolates were subsequently lost (Table 4). This observation alone triggered a review of the already stringent anaerobic laboratory process and quality control. No anomaly was reported from the regular surveillance of the facilities and no concurrent increase in unexpected sample loss was reported from other specimens. Quality check had negative findings and no similar situations were observed in other studies conducted during the same period (36). Based on 
these observations, we concluded that the findings of loss and non-identification were genuine.

An animal study is available in the literature on the effect of cyclosporin A on ligature induced periodontal breakdown in ferrets (8). An increase in spirochetes proportion up to $4 \%$ in the cyclosporin A pre-medicated 28-day ligature induced periodontal breakdown in ferrets was noted. One other report showed subgingival microbiology of nifedipine associated gingival overgrowth in human (20), whereas another study carried out a partial microbial evaluation of plaque at gingival margins with phenytoin related gingival overgrowth (32). A considerable proportion of spirochetes was also observed in the present study (Table 3), which was comparable to samples from periodontitis pockets (1) of normal patients. The subgingival cultivable microbial composition observed in the current study, however, contrasted with the corresponding observation of subgingival microflora associated with gingival overgrowth induced by nifedipine (20). In that study, the authors reported significantly higher prevalence of $C$. sputigena and $F$. nucleatum from gingival enlargement lesions. Despite the fact that most of the current subjects also receive calcium antagonists such as nifedipine to attenuate the nephrotoxicity of calcineurin inhibitors, the current anaerobic culture results, within the limitations of the study, did not support the notion that $C$. sputigena and $F$. nucleatum were associated with gingival enlargement lesion due to immuniosuppression therapy post-renal transplant. Instead, Capnocytophaga species, especially $C$. gingivalis, were prevalent in both groups, while a significantly lower prevalence of fusiform species was found in samples from subjects without periodontal destruction regardless of gingival overgrowth. This observation implied that other factor(s) might be in operation dictating the composition of the predominantly cultivable subgingival plaque flora in the current cohort. 
In the present study, Gram stained smears of the samples were also evaluated. The microscopic evaluation of the samples before the bacterial culture was relevant because spirochetes could not be isolated with routine anaerobic culture and the available spirochete isolation techniques could only purify a few treponemes (37). The importance of the complimentary or supportive role played by Gram stained smears in analysis of routine anaerobic culture result was already discussed in an earlier publication (16).

Regardless of the lost isolates, approximately $50 \%$ of the isolates were obligate anaerobes which is similar to proportion of earlier work from the current group regarding subgingival microflora of various periodontal conditions $(15,16)$. This observation also supports the argument that probably the anaerobic facilities were in normal function otherwise a larger proportion of facultative anaerobes should be observed. We postulate that some other causes are responsible for the increased lost isolates than failure in anaerobiosis. In the later case, much less or even no obligate anaerobes would be available after the primary culture and they probably would not survive and grow to form a colony. An alternate explanation for our observation is loss of satellite bacterial colonies after they had been subcultured. Microbial symbiosis or satellite growth was reported for oral and respiratory flora $(2,26,34)$. The special environment of the renal transplant subgingival niche might have fostered transformation of the subgingival microbial biofilm. The fact that the subgingival biofilm is much more complex than what could be appreciated from culture alone (21) indirectly indicated that such a proposition could not be overlooked.

In the subjects we studied, given the findings from our earlier study (6), it seems that the bacterial or fungal pathogens e.g. Nocardia, Listeria, Aspergillus, Cryptococus etc. which often cause post-transplantation infections in the local renal transplant recipients, are not recoverable from the subgingival niche. Further investigations with more control groups such as pre-renal graft individuals as well as normal control subjects are needed to determine 
if renal transplant recipients might habour a different or unique subgingival microflora. Specific non-culture sensitive techniques such as bacterial identification using 16S rRNA (21) maybe more appropriate in anticipation of the same frequency of loss of isolates that was encountered in this current study.

In conclusion, a high prevalence of gingival enlargement was observed in the present cohort of kidney transplant recipients. The subgingival microflora of the kidney transplant recipients, who were affected by periodontitis, comprise gram-negative rods and spirochetes. However, a considerable amount (up to $25 \%$ ) of the subgingival flora from the renal transplant recipients were not recoverable by anaerobic culture and a high prevalence of nonoral microbes were identified. Further studies with a lager renal transplant recipient patient group with periodontal status-, age-, and sex-matched controls, utilizing anerobic culture as well as culture independent bacterial identification methods are required to confirm the preliminary findings of this report.

\section{Acknowlegements}

The authors are grateful to Drs. Thomas Fu and Helena Wong who assisted with the clinical part of the study. We are also thankful to the staff hygienists of the Periodontology Clinic, Prince Philip Dental Hospital, who took good care of the recruits' periodontal health during the study and to Dr. Esmonde F. Corbet for help with the manuscript. 


\section{References}

1. Armitage GC, Dickson WR, Jenderseek RS, Levine SM, Chambers DW. Relationship between the percentage of subgingival spirochetes and the severity of periodontal disease. J Periodontol 1982: 53:550-556.

2. Bouvet A. Human endocarditis due to nutritionally variant streptococci: Streptococcus adjacens and Streptococcus defectives. Eur Heart J 1995: 16 (Suppl B):24-27.

3. Budde K, Fritsche L, Mai I, Bauer S, Smettan S, Waiser J, et al. Clinical pharmacokinetics of tacrolimus in rescue therapy after renal transplantation. Int J Clin Pharmacol Ther 1996: 34:493-497.

4. Carpenter CB, Lazarus JM. Dialysis and transplantation in the treatment of renal failure. In:, Frauci AS, Braunwald E, Isselbacher KJ, Wilson JD, Martin JB, Kasper DL, et al. ed. Harrison's principles of internal medicine. 14th ed. New York: McGraw-Hill Co, Chapter 272, 1998: 1520-1529.

5. Chan TM. Management of end-stage renal failure: a Hong Kong perspective. Chin Med J 1997: 110:431-437.

6. Chu FCS, Tsang PCS, Chan AWK, Leung WK, Samaranayake LP, Chan TM. Oral health status, oral microflora, and non-surgical periodontal treatment of renal transplant patients receiving cyclosporin A and FK 506. Ann R Australas Coll Dent Surg 2000: 15: $286-291$ 
7. European Mycophenolate Mofetil Cooperative Study Group. Mycophenolate mofetil in renal transplantation: 3-year results from the placebo-controlled trial. Transplantation 1999: 68:391-396.

8. Fischer RG, Edwarsson S, Klinge B, Attström R. The effect of Cyclosporin A on the oral microflora at gingival sulcus of the ferret. J Clin Periodontol 1996: 23:853-860.

9. Ho YW. Medical Complications after renal transplantation. The Hong Kong Med Diary 2001: 6(pt 4):12-15.

10. Kahan BD. Efficacy of sirolimus compared with azathioprine for reduction of acute renal allograft rejection: a randomized multicentre study. The Rapamune US Study Group. Lancet 2000: 356:194-202.

11. Kantarci A, Cebeci I, Tuncer O, Carin M, Firatlie E. Clinical effects of periodontal therapy on the severity of Cyclosporin A - induced gingival hyperplasia. J Periodontol 1999: 70:587-593.

12. King GN, Fullinfaw R, Higgins TJ, Walker RG, Francis DM, Wiesenfeld D. Gingival hyperplasia in renal allograft recipients receiving cyclosporin-A and calcium antagonists. J Clin Periodontol 1993: 20:286-293.

13. Koneman EW, Allen SD, Janda WM, Schreckenberger PC, Winn WC Jr. Miscellaneous fastidious gram-negative bacilli. In: Color atlas and textbook of diagnostic Microbiology. 5th ed. Philadelphia: Lippincott, Chapter 8, 1997: 395-472. 
14. Leung WK, Dassanayake RS, Yau JYY, Jin LJ, Yam WC, Samaranayake LP. Oral colonization, phenotypic, and genotypic profiles of Candida species in irradiated, dentate, xerostomic nasopharyngeal carcinoma survivors. J Clin Microbiol 2000: 38:2219-2226.

15. Leung, WK, Theidade E, Comfort MB, Lim PL. Microbiology of the pericoronal pouch in mandibular third molar pericoronitis. Oral Microbiol Immunol 1993: 8:306-312.

16. Leung WK, Jin LJ, Samaranayake LP, Chiu GKC. Subgingival microbiota of shallow periodontal pockets in individuals after head and neck irradiation. Oral Microbiol Immunol 1998: 13:1-10.

17. Leung WK, Jin LJ, Yam WC, Samaranayake LP. Oral colonization of aerobic and facultatively anaerobic gram-negative rods and cocci in irradiated, dentate, xerostomic individuals. Oral Microbiol Immunol 2001: 16:1-9.

18. McCauley J. Complications of renal transplantation. Medical complications. In: Shapiro R, Simons RL, Starzl TE, ed. Renal transplantation. Stamford: Appleton \& Lange, Chapter 11, 1997: 299-314.

19. McNabb H, Mombelli A, Gmür R, Mathey-Dinç, S, Lang NP. Periodontal pathogens in the shallow pockets of immigrants from developing countries. Oral Microbiol Immunol 1992: 7:267-272. 
20. Nakou M, Kamma JJ, Andronikaki A, Mitsis F. Subgingival microflora associated with nifedipine-induced gingival overgrowth (published clarification appears in J Periodontol 70:238, 1999). J Periodontol 1998: 69:664-669.

21. Paster BJ, Boches SK, Galvin JL, Ericson RE, Lau CN, Levanos VE, et al. Bacterial diversity in human subgingival plaque. J Bacteriol 2001: 183:3770-3783.

22. Peterson DE, Minah GE, Overholser CD, Suzuki JB, PePaola LG, Stansbury DM, et al. Microbiology of acute periodontal infection in myelocuppressed cancer patients. J Clin Oncol 1987: 5:1461-1486.

23. Pirsch JD, Miller J, Deierhoi MH, Vincenti F, Filo RS. A comparison of tacrolimus (FK 506) and cyclosporine for immunosuppression after cadaveric renal transplantation. FK 506 kidney Transplant Study Group. Transplantation 1997: 63:977-983.

24. Rams TE, Andriolo M Jr, Feik D, Abel SN, McGivern TM, Slots J. Microbiological study of HIV-related periodontitis. J Periodontol 1991: 62:74-81.

25. Rams TE, Roberts TW, Feik D, Molzan AK, Slots J. Clinical and Microbiological findings on newly inserted hydroxyapatite-coated and pure titanium human dental implants. Clin Oral Impl Res 1991: 2:121-127.

26. Ruoff KL. Nutritionally variant streptococci. Clin Microbiol Rev 1991 4:184-190. 
27. Schwarz E, Chiu GKC, Leung WK. Oral health status of Southern Chinese following head and neck irradiation therapy for nasopharyngeal carcinoma. J Dent 1999: 27:21-28.

28. Seymour RA, Ellis JS, Thomason JM. Risk factors for drug-induced gingival overgrowth. J Clin Periodontol 2000: 27:217-223.

29. Seymour RA, Smith DG, Rogers SR. The comparative effects of azathioprine and cyclosporin on some gingival health parameters of renal transplant patients. A longitudinal study. J Clin Periodontol 1987: 14:610-613.

30. Slots J, Rams TE. New views on periodontal microbiota in special patient categories. J Clin Periodontol 1991: 18:411-420.

31. Smibert RM, Krieg NR. Phenotypic characterization. In: Gerhardt P, Murray RGE, Wood WA, Krieg NR, ed. Methods for general and molecular bacteriology. Washington, DC: Am Soc Microbiol, Chapter 25, 1994: 607-654.

32. Smith QT, Wilson MM, Germaine GR, Pihlstrom BL. Microbiol flora and clinical parameters in phenytoin associated gingival overgrowth. J Periodont Res 1983: 18:5656.

33. Spratt H, Boomer, S, Irwin CR, Marley JJ, James JA, Maxwell P, et al. Cyclosporin associated gingival overgrowth in renal transplant recipients. Oral Dis 1999: 5:27-31. 
34. Stout JE, Best MG, Yu VL, Rihs JD. A note on symbiosis of Legionella pneumophilia and Tatlockia micdadei with human respiratory flora. J Appl Bacteriol 1986: 60:297299.

35. Timmerman LA, Clipstone NA, Ho SN, Northrop JP, Crabtree GR. Rapid shuttling of NF-AT in discrimination of $\mathrm{Ca}^{2+}$ signals and immunosuppression. Nature 1996: 383:387-340.

36. Tsang CSP, Samaranayake LP. Predonminant cultivable subgingival microbiota of healthy and HIV-infected ethnic Chinese. APMIS 2001: 109:117-126.

37. Wardle HM. The challenge of growing oral spirochaetes. J Med Microbiol 1997: 46:104-116.

38. Wondimu B, Dahllof G, Berg U, Moder T. Cyclosporim-A-induced gingival overgrowth in renal transplant children. Scand J Dent Res 1993: 101:282-286. 
Table 1. Demographic data, post-transplant duration and immunosuppressant usage of subjects.

\begin{tabular}{|c|c|c|c|c|c|c|c|c|c|}
\hline \multirow[b]{3}{*}{ Group } & \multirow[b]{3}{*}{$\begin{array}{c}\mathrm{n} \\
(\% \text { female })\end{array}$} & \multirow[b]{3}{*}{$\begin{array}{c}\text { Age range } \\
(\text { mean } \pm S D)\end{array}$} & \multirow[b]{3}{*}{$\begin{array}{l}\text { Years post- } \\
\text { transplant } \\
(\text { mean } \pm \mathrm{SD})\end{array}$} & \multicolumn{3}{|c|}{ Transplant donor } & & & \\
\hline & & & & \multirow[b]{2}{*}{ Cadaveric } & \multicolumn{2}{|c|}{ Living } & \multicolumn{3}{|c|}{ Immunosuppressant used } \\
\hline & & & & & $\begin{array}{c}\text { Not } \\
\text { Genetically } \\
\text { Related }\end{array}$ & $\begin{array}{l}\text { Genetically } \\
\text { Related }\end{array}$ & Cyclosporin A & Tacrolimus & None \\
\hline \multicolumn{10}{|c|}{ A (Subjects without periodontal destruction) } \\
\hline $\begin{array}{l}\text { No gingival } \\
\text { overgrowth }\left(A_{1}\right)\end{array}$ & $4(50.0)$ & $\begin{array}{c}30-41 \\
(35.4 \pm 4.6)\end{array}$ & $\begin{array}{c}0.5-5.6 \\
(2.5 \pm 2.3)\end{array}$ & 3 & 1 & 0 & 3 & 1 & 0 \\
\hline $\begin{array}{l}\text { With gingival } \\
\text { overgrowth }\left(\mathrm{A}_{2}\right)\end{array}$ & $7(42.9)$ & $\begin{array}{c}21-68 \\
(38.3 \pm 14.7)\end{array}$ & $\begin{array}{c}0.5-9.6 \\
(3.7 \pm 3.6)\end{array}$ & 5 & 1 & 1 & 6 & 1 & 0 \\
\hline Total & $11(45.5)$ & $\begin{array}{c}21-68 \\
(37.2 \pm 11.8)^{\mathrm{a}}\end{array}$ & $\begin{array}{c}0.5-9.6 \\
(3.3 \pm 3.1)\end{array}$ & 8 & 2 & 1 & 9 & 2 & 0 \\
\hline \multicolumn{10}{|c|}{ B (Subjects with periodontal destruction) } \\
\hline $\begin{array}{l}\text { No gingival } \\
\text { overgrowth }\left(\mathrm{B}_{1}\right)\end{array}$ & $16(43.8)$ & $\begin{array}{c}35-64 \\
(44.6 \pm 7.6)\end{array}$ & $\begin{array}{c}0.5-11.6 \\
(5.2 \pm 3.7)\end{array}$ & 13 & 2 & 1 & 13 & 2 & 1 \\
\hline $\begin{array}{l}\text { With gingival } \\
\text { overgrowth }\left(B_{2}\right)\end{array}$ & $11(36.4)$ & $\begin{array}{c}31-67 \\
(46.3 \pm 10.8)\end{array}$ & $\begin{array}{c}1.1-12.5 \\
(5.0 \pm 3.4)\end{array}$ & 8 & 0 & 3 & 11 & 0 & 0 \\
\hline Total & $27(40.7)$ & $\begin{array}{c}31-67 \\
(45.3 \pm 8.9)\end{array}$ & $\begin{array}{c}0.5-12.5 \\
(5.1 \pm 3.5)\end{array}$ & 21 & 2 & 4 & 24 & 2 & 1 \\
\hline
\end{tabular}

${ }^{a}$ Significant difference than subjects with periodontitis $(P=0.027$, analysis of variance). 
Table 2. Sampling sites ${ }^{\mathrm{a}}$.

\begin{tabular}{lcccccccc}
\hline & \multicolumn{3}{c}{ Group A } & & \multicolumn{3}{c}{ Group B } \\
\cline { 2 - 4 } \multicolumn{1}{c}{ Sample Sites } & $\begin{array}{c}\text { No Gingival } \\
\text { Overgrowth } \\
\left(\mathrm{A}_{1}\right)\end{array}$ & $\begin{array}{c}\text { With Gingival } \\
\text { Overgrowth } \\
\left(\mathrm{A}_{2}\right)\end{array}$ & Total & & $\begin{array}{c}\text { No Gingival } \\
\text { Overgrowth } \\
\left(\mathrm{B}_{1}\right)\end{array}$ & $\begin{array}{c}\text { With Gingival } \\
\text { Overgrowth } \\
\left(\mathrm{B}_{2}\right)\end{array}$ & Total \\
\hline Incisor/cainines & 4 & 2 & 6 & & 4 & 6 & 10 \\
Premolars & 0 & 2 & 2 & & 1 & 1 & 2 \\
Molars & 0 & 3 & 3 & & 11 & 4 & 15 \\
$\begin{array}{l}\text { Probing Depth } \\
\text { (mm) }\end{array}$ & $2.5 \pm 0.5$ & $6.2 \pm 0.6$ & $4.6 \pm 2.0$ & $5.3 \pm 1.1$ & $6.6 \pm 1.9$ & $6.0 \pm 1.7$ \\
\hline
\end{tabular}

${ }^{a}$ Group $\mathrm{A}=$ subjects without periodontal destruction;

Group B = subjects with periodontal destruction

${ }^{b}$ Measured with Florida Probe System. 
Table 3. Differential cell counts from Gram-stained smears ${ }^{\mathrm{a}}$.

\begin{tabular}{|c|c|c|c|c|c|}
\hline & \multicolumn{2}{|c|}{ Group A } & \multicolumn{2}{|c|}{ Group B } & $P^{\mathrm{b}}$ \\
\hline \multicolumn{6}{|c|}{ Gram-positive microorganisms ${ }^{c}$} \\
\hline Cocci & $0-50.5$ & $(1.5,21.1)^{\mathrm{d}}$ & $0-27.5$ & $(0,3.2)$ & 0.012 \\
\hline Rods & $0-10.5$ & $(0,2.2)$ & $0-24$ & $(0,2.0)$ & NS \\
\hline Total & $0-56.5$ & $(1.5,17.6)$ & $0-51.5$ & $(0.5,5.2)$ & 0.045 \\
\hline \multicolumn{6}{|c|}{ Gram-negative microorganisms } \\
\hline Cocci & $0-11.5$ & $(4,4.9)$ & $0-17.5$ & $(2.5,4.7)$ & NS \\
\hline Rods & $25-86.5$ & $(53.5,57.9)$ & $22-88.5$ & $(60.5,58.6)$ & NS \\
\hline Fusiforms & $0-7.0$ & $(1,1.9)$ & $0-2.5$ & $(1.5,1.4)$ & NS \\
\hline Curved rods & $0-4.5$ & $(1.5,1.9)$ & $0-60$ & $(2.0,2.4)$ & NS \\
\hline Filaments & $0-1.5$ & $(0,1.1)$ & $0-26.5$ & $(0.5,1.6)$ & NS \\
\hline Spirochetes & $0-44$ & $(11,14.8)$ & $0-66.5$ & $(24,26.1)$ & NS \\
\hline$\underline{\text { Total }}$ & $43-100$ & $(98.5,82.4)$ & $48.5-100$ & $(99.5,94.7)$ & NS \\
\hline \multicolumn{6}{|l|}{ Fungi $^{\mathrm{e}}$} \\
\hline Yeast form & 0 & $(0,0)$ & $0-20$ & $(0,0.1)$ & NS \\
\hline
\end{tabular}

a Group $\mathrm{A}=$ plaque samples from subjects without periodontal destruction; Group $B=$ plaque samples from subjects with periodontal destruction

${ }^{b}$ Analysis of variance. NS = not significant.

c No gram-positive filaments observable.

${ }^{\mathrm{d}}$ Data shown are percentage range, and in parenthesis: median and mean

e No mycelial form observable. 
Table 4. Prevalence of microbes isolated and the corresponding mean percentage isolation from subgingival plaque samples of renal transplant recipients ${ }^{\mathrm{a}}$.

\begin{tabular}{|c|c|c|c|c|}
\hline & \multirow[t]{2}{*}{ Group A } & \multirow[t]{2}{*}{ Group B } & \multicolumn{2}{|c|}{$P$} \\
\hline & & & Prevalence $^{\mathrm{b}}$ & $\begin{array}{l}\text { Percentage } \\
\text { Isolation }\end{array}$ \\
\hline \multicolumn{5}{|l|}{ Gram-positive } \\
\hline \multicolumn{5}{|l|}{ Facultative anaerobic cocci } \\
\hline Gemella haemolysans & $18.2(1.7)^{d}$ & $7.4(1.5)$ & NS & NS \\
\hline Gemella morbillorum & $27.3(3.2)$ & $40.7(4.6)$ & NS & NS \\
\hline Streptococcus constellatus & $36.4(5.5)$ & $3.7(0.1)$ & 0.019 & 0.009 \\
\hline Streptococcus mitis biovar 1 & $27.3(2.0)$ & $18.5(1.3)$ & NS & NS \\
\hline Streptococcus sanguis & $18.2(3.0)$ & $7.4(0.2)$ & NS & NS \\
\hline $\begin{array}{l}\text { Streptococcus salivarius } \\
\text { salivarius }\end{array}$ & $27.3(3.6)$ & $7.4(0.7)$ & NS & 0.002 \\
\hline \multicolumn{5}{|l|}{ Anaerobic cocci } \\
\hline Peptostreptococcus micros & $27.3(3.0)$ & $25.9(5.1)$ & NS & NS \\
\hline Peptostreptococcus prevotil & $27.3(2.1)$ & $11.1(0.6)$ & NS & NS \\
\hline \multicolumn{5}{|l|}{ Facultative anaerobic rods } \\
\hline $\begin{array}{l}\text { Actinomyces georgiae/ } \\
\text { gerencseriae }\end{array}$ & $0(0)$ & $22.2(2.6)$ & NS & NS \\
\hline Actinomyces naeslundii & $18.2(3.0)$ & $11.1(0.6)$ & NS & NS \\
\hline Arachnia propionica & $18.2(1.2)$ & $25.9(4.2)$ & NS & NS \\
\hline Lactobacillus jensenil ${ }^{e}$ & $9.1(4.4)$ & $18.5(1.7)$ & NS & NS \\
\hline Rothia dentocariosa & $18.2(3.8)$ & $0(0)$ & NS & NS \\
\hline \multicolumn{5}{|l|}{ Gram-negative } \\
\hline \multicolumn{5}{|l|}{ Anaerobic rods } \\
\hline Actinomyces israelii & $0(0)$ & $18.5(3.7)$ & NS & NS \\
\hline \multicolumn{5}{|l|}{ Anaerobic rods } \\
\hline Campylobacter gracilis & $27.3(2.2)$ & $33.3(5.2)$ & NS & NS \\
\hline Campylobacter rectus & $0(0)$ & $22.2(3.7)$ & NS & NS \\
\hline Prevotella corporis & $9.1(3.4)$ & $33.3(1.5)$ & NS & NS \\
\hline Prevotella intermedia & $9.1(0.6)$ & $18.5(1.1)$ & NS & NS \\
\hline \multicolumn{5}{|l|}{ Facultative fusiforms } \\
\hline Capnocytophaga gingivalis & $18.2(1.5)$ & $22.2(3.9)$ & NS & NS \\
\hline Capnocytophaga ochracea & $0(0)$ & $22.2(2.4)$ & NS & NS \\
\hline Non-oral ${ }^{f}$ & $36.4(15.6)$ & $51.9(10.1)^{\mathrm{g}}$ & NS & NS \\
\hline Lost/unidentified spp. & $63.6(17.9)^{\mathrm{h}}$ & $81.5(25.6)^{i}$ & NS & NS \\
\hline
\end{tabular}

${ }^{a}$ Only species with frequency of isolation $>15 \%$ in any one group are included. Group $\mathrm{A}=$ plaque samples from subjects without periodontal destruction; Group $B=$ plaque samples from subjects with periodontal destruction. Except indicated, all median values $=0 \%$.

${ }^{b}$ Fisher's exact test

c Analysis of variance.

${ }^{d}$ Data shown are percentage prevalence and mean (in parenthesis).

e Microbes that are not normally considered as member of the oral or oropharyngeal flora.

${ }^{f}$ Data including species with frequency of isolation $\leq 15 \%$.

g Median $=3.1 \%$

${ }^{h}$ Median $=7.1 \%$

i Median $=14.7 \%$ 


\section{FIGURE LEGEND}

Fig. 1. Relative mean proportion of predominant cultivable bacterial types from subgingival plaque samples of renal transplant recipients. Group $\mathrm{A}=$ plaque samples from sites without periodontal breakdown; Group B = plaque samples from sites with periodontal breakdown. *The percentage proportion of gram-positive facultative anaerobic cocci was significantly different between the two groups ( $P=0.006$, analysis of variance). 
Group A

Group B

Gram-positive species

Facultative anaerobic cocci

Anaerobic cocci

Facultative anaerobic rods Anaerobic rods

Facultative anaerobic filaments

Gram-negative species

Facultative anaerobic cocci

Anaerobic cocci

Facultative anaerobic rods/filaments

Anaerobic rods/filaments

Facultative anaerobic fusiforms

Anaerobic fusiforms

No growth

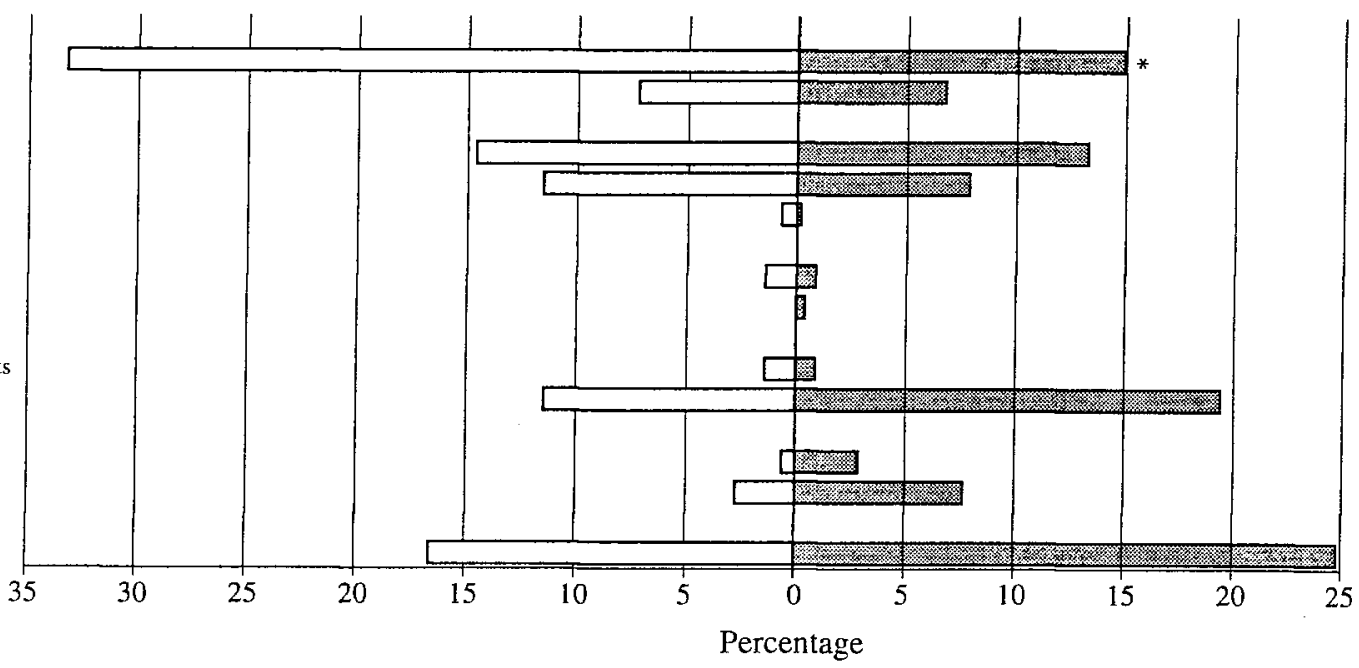

